\title{
The Survival Theme of the Science Fiction "The Three Body Problem” Trilogy from Cixin Liu
}

\author{
Chuwei Wang \\ School of Literature and Communication \\ Huizhou University \\ Huizhou, China 516007
}

\author{
Ting Li \\ School of Literature and Communication \\ Huizhou University \\ Huizhou, China 516007
}

\begin{abstract}
The science fictions of Cixin Liu are spoken highly of people for they make science fiction into reality, using grand imagination and narration to express the charm of the universe and unique humanistic concern. However, fewer scholars interpret works from the survival aspect and it leaves a certain amount of space for the study of this thesis. On the basis of the analysis and reference of the research results and newspaper interview, this thesis centers on the root and specific content of the existence idea of Cixin Liu, which believes survival is superior to everything. It takes "The Three Body Problem" for example, analyzing and summarizing the grant survival and individual survival in the fiction, expressing the worldly thought of humanity and survival, to shock the existing moral standard and show a different thinking dimension to readers.
\end{abstract}

Keywords-"The Three Body Problem" trilogy; Cixin Liu; survival theme

\section{INTRODUCTION}

Survival is defined in the modern Chinese dictionary as: preservation of life, as opposed to "death" [1]. Related to this, from the perspective of existentialism, its Latin existentia, means existence, survival, and subsistence, thus existentialism is also called Survivalism [2]. Sartre's existentialism believes that "the existence precedes the essence", arson first is "existing", only later the person himself wants to become something, so he creates himself according to his own will, except for the survival of man, there is no natural morality or in vitro soul. Morality and soul are all created by human beings during existence. People are not obliged to obey certain moral standards or religious beliefs, people have the freedom of choice [3]. As a representative of China's hard science fiction, Cixin Liu's "Three Body Problem" Trilogy is as always with its magnificent imagination and grand narrative, using physical laws to show us the beauty of science and technology, and exploring the grand proposition of humanity and survival in the text. It is a milestone in Chinese science fiction literature.

As the most important sci-fi series of novels in China's core science fiction, the study of "Three Body Problem" Trilogy in the academic circle is still not too much. In 2015, the "Three Body Problem" Trilogy won the Best Full-length Novel in the 73rdHugo Award, when it was nominated by the Nebula Award in the same year, it once had a "Three Body Problem Fever", and public's attention to science fiction novels also increased. In the existing researches, some of the researchers is from the perspective of science fiction and reality in the creation of science fiction literature, such as Chen Xin's "Civilization Conflict and Cultural Consciousness - Science Fiction and Reality of Three Body Problem" (2016) [4]; Some from the perspective of technology and human care, such as Liu Yuan's "The tension of scientific thinking and humanistic self-examination - Comment on Cixin Liu's 'Three Body Problem' Trilogy" (2016) [5]; Some from the perspective of world outlooks, such like Luo Yinan's "Affection in the Unreal Universe - Analysis of Human Instinct in Cixin Liu's Works" (2008) [6], etc., and study from the perspective of writing techniques, many of them is to study the "macro details" and "time jump" in the Narrative techniques, such as Wang Jingjing's "On the Cultural Revolution Narrative in Cixin Liu's "Three Body Problem'" (2016) [7]. In general, the study of the "survival theme" that runs through the entire series is still rare, normally they are interspersed in the discussion as evidence.

This paper will focus on the proposition of humanity and survival in the novel, through the fine reading of the novel, discusses the "Survival theme" of the novel from the macroscopic civilization survival and the individual survival these two aspects, analyzes the basic starting point creation of Cixin Liu's "survival theme" and the specific content and deep thinking of Cixin Liu's concept of survival.

\section{The GENERATION AND THINKING OF CIXIN LIU'S CONCEPT OF SURVIVAL "SURVIVAL FIRST"}

The "Three Body Problem" Trilogy is also known as the "Past of Earth" Trilogy. From the word "past" in the name of the novel, it indicates the annihilation of the earth, on the macro level, this is a survival history of earth civilization. Cixin Liu's theme of "survival" in the "Three Body Problem" Trilogy runs through the characters shaping of the whole work and the coexistence patter of the comic civilization. Then we can't help thinking about the generation of this theme creation and Cixin Liu's " unique thinking of the word "survival", it will explain from Cixin Liu's life and Cixin Liu's concept of existence in the following.

\section{A. The Generation of the Concept of Survival "Survival First": the Influence of Writers' Real Life}

In 1963, Cixin Liu was born in Beijing, his ancestral home is Henan. His father was an old soldier, there was a plague of locusts during the anti-Japanese war, his father lived without a 
dependency, so he fled to the "communist army" and has been battled in the front line. Countless people died in those brutal wars, so in the end, as long as they lived, they could become officials. So his father became a junior officer and was transferred to the Beijing Coal Mine Design Institute as a cadre, where he married and had children. Later, during the "Cultural Revolution" period, he was implicated by the brothers who had joined in the Kuomintang army, Cixin Liu's family was driven out of Beijing to a coal mine in Yangquan, Shanxi. His father was a miner and his mother was a primary school teacher, Cixin Liu began his study there. After graduating from the North China University of Water Resources and Electric Power, he was assigned to a thermal power plant as a computer engineer [8]. Cixin Liu's life experience is as simple as he said, but it is not difficult to see some of the shadows in the novel of "Three Body Problem I". For example, Cixin Liu's family story during the Cultural Revolution was displayed indirectly through the character shaping of Ye Wenjie.

Similarly, in the interview with Cixin Liuby Beijing Youth Daily in 2015, Cixin Liu admitted that his former sci-fi was relatively sunny, until to the "Three Body Problem" it became so dark, this change reflects his personal experience tortuously. One of the descriptions is that "Before I wrote "Three Body Problem', our company was smooth sailing, with good income and stable work, but when I wrote 'Three Body Problem', it caught up with Copenhagen and promised to reduce emissions, so the power system began to have big surgery, even our medium and large electric fields have to be closed... Our company has 2,000 people, a new large power plant can only accommodate 400 people, where are the rest 1600 people going? Under this atmosphere, the style of 'Three Body Problem' has become a bit dark and the competition for survival has surfaced" [9]. Therefore, it is undeniable that Cixin Liu's experience has a projection effect on the creation of "Three Body Problem".

Whether it is the reason his father joined the army and the cruel war experience, or the writer's own work experience, Cixin Liu's subconscious mind particularly values life survival. His fathers joined the army for survival, and used his life to earn food, this is forced by life, and "as long as you live, you can be an official "means you only have a future after you survived. Survival is the first priority; the word "survival" is always a topic that his father can't escape in his life. The experience of his father was projected into the novel, and formed the principle of action of the soldiers such as Zhang Beihai, the Blue Space and the Bronze Age which fight for survival not honor, and the plot setting of killing each other for survival. The survival competition in the real life of the writer is consciously or unconsciously projected into the creation of science fiction, so there is a survival game between the human civilization and the Three Body Problem civilization in the "Three Body Problem" trilogy, and the survival theme was born from it.

\section{B. The Core Content of the Concept of Survival "Survival First" and the Earthly Thinking}

Science fiction is divided into two types: hard science fiction and soft science fiction. It is different from Han Song, $\mathrm{He} \mathrm{Xi}$, Ni Kuang and other soft sci-fi writers who mainly express human relationships, with philosophy, psychology and sociology as the main plots and materials. Cixin Liu, a science and engineering graduate writer, his science fiction belongs to a hard science fiction based on natural sciences such as astronomy, physics, geology, biology, etc., it focuses on the impact of technology on human society, and science is the feature of hard science fiction. Cixin Liu is fundamentally a crazy technicalist, he firmly believes that technology can solve all problems [10]. His survival theme is based on the technical strength, and naturally it is dominated by the stable knowledge system of science, it is calm and purely rational, "human beings outperformed science and technology ethics" is his most disgusting view. On the issue of "humanity or survival", Cixin Liu had a dialogue with Jiang Xiaoyuan, the current director of the Department of Science History of Shanghai Jiaotong University in 2007. In the conversation, Cixin Liu pointed out a question for the magazine reporter who recorded for them, "If there are only three people left in the whole world, they must eat her so both of them two can survive, will they eat her or not?" Jiang Xiaoyuan said that he chose to unite three people, he will not eat her even if they die, because without humanity and demise are the same, but Cixin Liu said that he will certainly eat her" [10].

In Cixin Liu's concept of survival, he believes in the idea of "Survival first". In order to survive, he can abandon humanity and abandon morality, by fair means or foul. It can be said that this almost shameless survival concept is contrary to the existing mainstream concept it is deviant, but Cixin Liu's concept is rarely criticized by people because it has an indispensable premise, that is based on the extreme survival crisis. Cixin Liu has a doomsday complex, whether it is the "Country Teacher" published in 2001 [11] or the "Wandering Earth" published in 2008 [12], in his many works, Cixin Liu always likes to place human civilization in the extreme living environment on the edge of destruction, in the crisis of survival, question the place of humanity and survival, thus impacting our existing moral system. He believes that "the so-called morality is just an expedient measure of collective survival, it changes with the environment, so it is not so sacred at all [13]. Indeed, looking back at the history of mankind, human morality and values are not eternal. In the primitive society, people's intelligence is not open, so they follows the natural choice of winning and defeating, there is no moral at all. In feudal society, the Confucian hierarchical ethical order, men are superior to women are the ethical principles that were believed at the time, and these ethical principles are all dross placed in current times. It can be seen that human nature is undoubtedly in the process of development and evolution, and all moral standards are born in accordance with the times, so it is also all for survival. In the war period, we judged that this was a shameless act of traitors, but it may be the only law that can be pursued at the doomsday. What Cixin Liu admires is the "survival" of abandoning humanity and morality under this rational domination. Between the real life and the imaginary morality, the needs of survival transcend everything, that is "Survival first".

Secondly, in Cixin Liu's survival concept, there is also a view of universe zero morality, or the dark forest theory. In 1950, Nobel Prize winner, physicist Fermi proposed a Fermi 
paradox that the earth is a very young planet, the probability of the existence of extraterrestrial civilization in the universe is high, and the degree of civilization is likely to be higher than earth. Now that the Earth has a certain ability to explore and navigate in outer space, the technical level of extraterrestrial civilization will only be higher than that of human beings, but why haven't we seen them so far? And Cixin Liu puts forward a possibility in the "Three Body Problem II" with the dark forest theory, he believes the universe is zero morality, there is a competitive relationship between civilization and civilization, and there is no possibility of harmonious symbiosis. Exposing your own existence in the universe, whether your starting point is good or malicious, the most economical and effective way for other civilizations to protect themselves is to immediately eliminate the other side immediately, so humans have not been able to discover the existence trace of other civilizations. In this theory, survival is the first need of civilization. For the development of civilization, all potential or existing threats must be killed, others are hell. Therefore, the universe zero morality view is also an extension of "Survival first".

Moreover, in Cixin Liu's survival concept, there is also a view to explore space for the continuation of civilization. Nowadays, our living environment is increasingly damaged. Every bustling city is surrounded by polluted rivers, deforested forests, the earth's non-renewable resources are decreasing, and the earth's carrying capacity will eventually be unable to support the huge social population. At present, environmental protection is the only solution to solve the problem of environmental pollution. However, in Cixin Liu's view, the reduce expenditure is not as good as broaden the resources, compared with environmental protection; he is more inclined to space development. Except the influence caused by human activities can be turned by environmental protection, other living environment of the earth, such as the sun and other environmental change caused by the non-human factors is difficult to control, so once faced with the threat of survival that cannot be recovered by manpower, for the continuation of civilization, the development of space is the only feasible solution, the path of space exploration is the fate of mankind. Therefore, whether humans use the earth engine to escape to the universe in the "Wandering Earth", or the trinity and human beings finally give up the other planet and wondering in the universe in the "Three Body Problem", it is all revealing Cixin Liu's own value choice. This point of view of space exploration for the continuation of civilization is actually an implementation path and direction of "Survival first".

\section{GRAND SURVIVAL - THE DESTRUCTION AND PRESERVATION OF CIVILIZATION}

As a kind of literary category, science fiction literature has been separated from mainstream literature for a long time and is difficult to be accepted by mainstream culture. For the reason, we can easily find that reviewing the development history of human society for thousands of years, it is actually the rise history of human status. Therefore, in literature, "literature is human literature", characters as an integral part of traditional fiction, is an indispensable part, and literature without characters is difficult to be accepted by mainstream literature. But for science fiction literature, science is the foundation of the survival and foothold of science fiction literature. The existence and shaping of characters are greatly weakened compared with mainstream literature [10], some characters exist only as a symbol or there is no character in the whole article. As one of the top three sci-fi giants in the world, Arthur Clarke's work "2001: A Space Odyssey" (1968) is a representative of them. In the novel, there is only the moonwatcher monkey, the scientist Freud, the astronaut Poole and David these characters, and the characters are flat without distinct figure characteristics, their existence seems only to be a tool for promoting the development of the plot. What is even more exaggerated is that the famous director Kubrick directly symbolized the two astronauts in the adapted movie which published in the same year and with the same name of the novel, the only difference is the name. This weakening of people is difficult to be accepted in mainstream literature, but in the history of science fiction, "2001: A Space Odyssey" is still a well-deserved milestone.

As a series of novels of China's core science fiction, "Three Body Problem" has two main characteristics in the shaping of characters: on one hand, it slightly caters to the aesthetics of mainstream literature, and has more vivid characters than "2001: A Space Odyssey", but it is typed; on the other hand, it replaces the personal image with the entire ethnic image [10], the three tribal images such like human civilization, Three Body Civilization and the singer civilization in the "Three Body Problem" trilogy all exist as a grand whole, which is different from the mainstream literature of people, it describes the survival game between civilization and civilization from a macro perspective, which is also the biggest feature of science fiction.

\section{A. Survival Invasion of the Three Body Civilization}

The Three Body civilization is a civilization with three suns and 11 planets in the description of the novel. However, because of the irregular operation of the three suns, 10 planets have been swallowed up, and the only remaining planet is also in the midst of the crisis of being swallowed up at any time. This is a harsh living environment, so the Three Body people can only survive the high temperature of the surface through individual dehydration storage and waiting for a suitable living environment, this premise setting is also in line with Cixin Liu's consistent doomsday complex. In the Three Body world created by Cixin Liu, survival is also the premise of everything. "Three-body people" try to eliminate all emotions and avoids the spiritual vulnerability of individuals and society brought by emotions. This is a species without emotions such as fear, sadness, happiness, beauty, etc., they are numb and calm" [14], they believe that the civilization pursuit of love and beauty is the most fragile and short-lived. The whole Three Body civilization is built around the ultimate concept of "survival". Once people have no value, dehydration is the only ending, which is an extremely cruel survival mode. However, the Three Body civilization also once had the prevalence of literature and art, the people at that time were still very emotional, pursuing beauty and freedom. It was an era without survival troubles, but when the end is coming, all the fun must give way to survival. The Three body people abandoned literature, art these accessory of survival, and this huge cultural 
transformation is also the embodiment of Cixin Liu's "Survival First" survival concept in the doomsday era.

In Cixin Liu's view, when the existing resources are not enough to support the development of civilization or the living environment is no longer suitable for living, colonization to the universe is a natural choice for civilization. Therefore, when the Three Body civilization is in such a predicament of survival, receiving the message from the earth is undoubtedly a major turning point in fate, and this civilization is as fragile and beautiful as the Three Body Civilization was before. Driven by "survival", the Three Body people sent the fleet to leave the mother planet, aiming at colonized the earth, and began the journey of civilization survival. It also conformed to the idea that "space exploration is a human destiny" in Cixin Liu's survival concept.

\section{B. The Survival Struggle of Human Civilization}

The survival road of the Three Body civilization is the death journey of human civilization. The civilization and civilization are the competitive relationship, low-level civilization may surpass the higher civilization in a short period of technology explosion. In order to prevent the technological explosion of the earth civilization, Three-Body people launched Gao Weizhizi to disrupt the earth's basic physics experiments, affecting the development of the entire scientific field, while accelerating the reception process of the Three Body world to the Earth through the anti-human Three Body organization. Faced with the approach of the Three Body fleet, the blockade of basic science, and the suicide of scientists, human beings have fallen into an unprecedented dilemma. Faced with this dilemma, mankind began to appear as a whole image of the "United Nations" and the "United Nations Planetary Defense Council", the countries have formed a community of destiny, without the difference between countries and facing the survival of all mankind together. Later, it carried out various strategic deployments such as the Guzheng plan, the Mianbi plan, the Jieti plan, the bunker project, and the formation of the space fleet. It is allencompassing and intended to be the last self-help and struggle before the arrival of the Three Body fleet.

The Guzheng plan hit the Earth's Three Body organization, and the Mianbi plan made humans get the bargaining chip to negotiated with the Three Body people for coexistence, the Jieti plan made Yun Tianming enter the inside of Three Body people, and to some extent, these plans all received certain effect, but the process or consequences of each strategic deployment is an impact on humanity and morality. In the Guzheng plan, all ships and the members of the Earth's ThreeBody organization were instantly sliced by nanolaser. Among them include the sacrificed pilots and the ignorant crew, but the participants in the plan thought about how to optimize the people on board instead of saving these innocent people. When the plan was successful, it is "a kind of relax with bloody smell" [14]. What is even more shocking is that when the human space fleet is almost eliminated by the Three Body" water droplets", and the surviving spacecraft in the fleet is determined to never return to Earth, the "Blue Space", "Bronze Age", "Gravity" and other spacecraft aimed the muzzle at the companions, killing each other, and use their companions' parts and bodies as the support material to support their own voyage. At this time, the "human" was "alienated" and the traditional morality was completely broken. However, these people have become the last flames of human civilization. Therefore, it must be said that every major turning point in the last days of human beings is almost at the expense of humanity and morality, and these struggles for survival are all contains unspeakable blood and tears.

\section{The Devastating Blow of the Singer Civilization}

The Singer civilization is different from the Three Body civilization and the human civilization. There is very little ink for it in the novel, but it represents the high-end civilization in the universe civilization, it is the epitome of the high-end civilization, and the Singer civilization is more of a symbolic effect. High-end civilization like the Singer civilization, they ruin a civilization as simple as pinching an ant without any psychological burden. The description in the article is, "The Singer cleaners take out the 'two-way foil' from the warehouse, throwing it to the earth carelessly" [15], and this careless act caused the destruction of the entire solar system. The high-end civilization has the ability to destroy other civilizations, and is able to judge weather the civilization is good or evil. However, among many civilizations, the judgment between civilization and civilization is also different, so regardless of good and evil, the exposure of coordinates is always a dead end. So when human beings face the counterattack of the Three Body civilization, they retaliate to launch the coordinates of the earth and the Three Body world to the universe. In fact, they embark on a path of seeking death, so the results that the Singer civilization attacked the entire solar system include the earth and other civilizations destroyed the mother planet of the Three Body civilization is all the result of the expectation.

For all civilizations of the universe, the survival theory they followed is the dark forest theory, "The universe is a dark forest, and every civilization is a hunter with a gun... He must be careful, because the forest is full of hunters like himself, if he discovers another life, there is only one thing he can do: shoot and destroy it. In this forest, others are hell, it is an eternal threat, and any life that reveals its existence will soon be wiped out, this is the picture of the universe civilization". [16]. There is no morality in the cosmic society, the good society which everyone is happy does not exist here, hide yourself and wipe out the enemy. This is the most economical and safe survival criterion.

On the other hand, the development of three civilizations: Three Body civilization, human civilization, and Singer civilization, all reveal Cixin Liu's personal survival concept. Although the Three Body and human beings differ in biological form and structure, the Three Body civilization is more like a high-order form of human civilization. It is a growth version of human civilization in an extreme environment, the fate of the Three Body civilization is the epitome of the fate of human civilization. The Three Body civilization once pursued beauty and freedom just like human civilization, but when doomsday came, the Three body people abandoned the surviving accessories and pursued the "survival first", this has the same goal with human civilization abandoned the human morality in the survival crisis. This 
choice is also in line with Cixin Liu's value orientation of "survival is higher than human morality". The existence of the Singer civilization is to support the "Universe zero morality", to construct a simple model of the universe with three civilizations, to depict a real-world map of the universe with their development and evolution, and ultimately to explain the concept of "Survival first".

\section{INDIVIDUAL SURVIVAL AND TYPE CHARACTER SHAPING}

Cixin Liu's sci-fi creation is divided into three stages. The first stage is a pure science fiction stage, which is completely uninteresting in the people and the society; The second stage is the stage of human and nature, it describes two distinct worlds of the real world and the science fiction world, and explores the relationship between human and nature under the collision between the two worlds, the "Three Body Problem I" is at this stage; The third stage is the social experiment stage, which strongly describes the human behavior and social form in the extreme environment, the good and evil in sci-fi can find corresponding images in the real world [10]. The "Three Body Problem II Dark Forest" explores the relationship between people in the big universe, and "Three Body Problem III Death forever" is his further deduction of the sociology of the universe.

From "Three Body Problem I" to "Three Body Problem II Dark Forest" to "Three Body Problem III Death forever" is different from the weakening of the individual image of "2001: A Space Odyssey". Although Cixin Liu wrote human beings as a macroscopic whole, however there are also outstanding individual figures. These characters are typed, according to the humanity, survival and environmental protection factors involved in Cixin Liu's concept of survival, they can be roughly divided into three categories: one is The disappointing species betrayers represented by Ye Wenjie and Evans; The second is The firm survivalist represented by Thomas Weed and Zhang Beihai; The third The pursuer of humanity and love represented by Cheng Xin, and will be analyzed one by one.

\section{A. The Disappointing Species Betrayers}

Undoubtedly, sending earth coordinates, Ye Wenjie who calling for Three Body civilization, hope that the Three Body civilization replaces the earth civilization is a crazy sociopath, and Evans who established the Earth Three Body Organization and gathering intellectuals who are disappointed with human civilization through the Three Body game is undeniably a civilized betrayer. Rome was not built in one day, and their disappointment with human species is not without roots.

Ye Wenjie's father was a professor of physics, in the moral disorder ear of the Cultural Revolution, her mother betrayed and defiled her husband in order to survive, which causing Ye Wenjie's father beaten to death on the spot by the Red Guards. The young Ye Wenjie saw the whole process, her mother's betrayal, the persecution of the society made Ye Wenjie saw the selfish and unethical side of human beings. The chaos in the entire Cultural Revolution made Ye Wenjie completely desperate for human beings, so she wrote the message sent to the Three Body people that:"Come here, I Will help you to get this world, my civilization has been unable to solve its own problems, and we need your strength to intervene" [14]. From Freud's psychoanalysis, personality is divided into self, ego and superego. Spiritual injury makes Ye Wenjie's self dominated by evil and extremely hostile to human beings, so she instinctively stands on the opposite side of human beings and intent to destroy humanity, but in Ye Wenjie's moral logic, she also firmly believes that a more scientific and prosperous civilization will have a higher level of civilization and morality, so even if she is finally judged, she still believes that she is on the right path. She hopes that the moral level of the Three Body civilization will eliminate the evil of mankind. This is the goodness on the superego level, the evil of the self and the goodness of the superego constitute the complex figure of $\mathrm{Ye}$ Wenjie.

Evans is an out-and-out species communist. He believes that all species on earth are born equal, saving a kind of bird or insect is no different from saving human beings. Life is equal, the rich Evans saw the oil leakage in the United States, seabirds die quickly due to pollution, but these lives are not as good as human enjoyment. Evans, who cannot accept this fact, came to the mountain villages of China and came to the East which believe in Buddhism and believe all life is equal. He kept planting tress to save an endangered local bird and played the role of savior in the mountains. However, the cruel reality once again shattered his belief that the locals began to cut down the trees he planted for development. He finally found that even in the East, all human beings are the same, the desperation for human species and the hopelessness of saving other species eventually led him and Ye Wenjie to reach a consensus and completely abandon this inferior race.

In the characterization of Evans, Cixin Liu subtly explored the existing living environment, "In the game rules of human civilization, we must first ensure the survival of human civilization and the comfort of life, and the rest are all secondary". In order to seek rapid economic development, human beings with such thoughts seek benefits with environmental pollution and extinction of species, and finally encounter the doomsday crisis. This is more like karma, so even Evans and Ye Wenjie betrayed humans, but these two characters will not make readers feel resentful. Cixin Liu's plot setting can be said to be a kind of vigilance against reality.

\section{B. Rational Survivalist}

In the modern Western religious philosophy, there is a representative genre called Survivalist Religious Philosophy. It mainly uses the theme formed by the analysis of human beings and the marginalized existence of the human beings to reveal a sacred existence or the possibility of surpassing the individual's living state [17]. Although the core of science fiction is science and it is a firm atheistic novel, science fiction is somewhat equivalent to modern mythology. In "Three Body Problem", the almost sacred existence of this kind of existential religious philosophy is Zhang Beihai.

Nietzsche said that there must be Superman, so there is Zhang Beihai, who is a hidden core figure in the "Three Body Problem" novels that is not much inked but extremely important. Zhang Beihai is a Chinese soldier, as early as the 
construction of the "Tang" spaceship, he realized the fact that mankind will fail in the war with the Three Body people, and firmly believes that Escapism is the only way out. At that time, society considered Escapism is a tendency to fight against humanity, so Zhang Beihai disguised himself. His conviction for the future war is chilling, and he voluntarily enters hibernation with the conviction of desperate struggle, waiting to reach his own goal during the doomsday war after four hundred years. In order to meet the strategic needs, Zhang Beihai was awakened in advance. He quietly assassinated three unrelated people, after controlling the "Natural selection" spacecraft on the eve of the Doomsday War, he did not hesitate to make the order of the whole ship fleeing to the depths of the universe which clearly betrayed the instruction from fleet. At this point, Zhang Beihai's true idea which was hidden for more than two hundred years was uncovered. The facts afterwards also prove that Zhang Beihai's escape command is wise. He is an unfathomable and rational person, in order to preserve the finest fires of human civilization, he can betray the mainstream society and spend hundreds of years disguising himself. This is a steel-like will.

When the space army defeated and the surviving fleet fled everywhere, facing the survival, Zhang Beihai forced himself to order the attack command to other surviving fleets, only because the existing food and parts loss on the spacecraft could not support the space wondering for the entire fleet, if you want to survive, you must kill each other, but even because his personal hesitation, it is a few seconds later than the rest of the flee to make the decision, it causing the Natural selection to become the victim of other spaceships. The last sentence before his death was still: "It doesn't matter, it's the same" [16], which shows Zhang Beihai's image and will detached from human beings. Zhang Beihai has always been strategically planning from the standpoint of the entire human race and has devoted his whole life achieving his goals. Even if he sacrifices some human beings including himself to save the entire civilization, he abandoned human moral, legal and humanity, let the rational "survival" carry out his entire life, this is a modern Prometheus, leaving the fire to humans and leaving sin to himself.

Thomas Weed, who is the director of the Strategic Intelligence Bureau of the United Nations Stellar Defense Council, is also a crazy person. For strategic purposes, he can shoot Cheng Xin without hesitation in case to avoid Cheng Xin this mentally weak and has no threat to Three Body people to won the election during the Second Swordman Election. Also he chose survival over humanity when human beings only have to abandoned humanity so that they could research and develop the light speed spaceship driven by the beast nature. If Zhang Beihai is to abandon morality for the survival of human civilization, then Weed abandoned humanity for the freedom of man and the freedom of being a cosmic person. These two people are the same kind of people, they are out-to-out survivors. The shaping of the two characters is based on the Cixin Liu's survival concept "survival first" as the blueprint. Survival is the only spiritual belief, for this reason, you can choose to abandon humanity and maximize the chance of survival.

\section{The Pursuer of Love}

Cheng Xin is a widely criticized character in Cixin Liu's whole series on "Three Body Problem", it is a virgin Mary image in the name of love, "She was in the position of God twice, but twice she pushes the world to the abyss in the name of love" [15]. For the first time, Cheng Xin elected the swordman and was elected successfully. However, fifteen minutes after she had just hand over the scepter from Luo Ji, the Three Body civilization officially occupied the earth, and human beings were rushed to Australia to fend for themselves. In the meantime, she was unable to press the button to make a decision to launch coordinates, and she threw away the launcher because of fear, completely lost the bargaining chip with the Three Body people. The second time, human beings learned that the survival choices of earth civilization are: bunker, black field and light speed spacecraft three ways, after Cheng Xin knows that the development of light speed spacecraft will produce a small range of black filed and endanger human life, she asked Weed to give up the experiment, even if Weed said "losing humanity, losing a lot, losing the animal nature, losing everything", Cheng Xin's answer is still "I choose human nature" [15]. It is precisely because of this choice of Cheng Xin that she blocked the true survival path of the light speed spacecraft, and the Earth and even the solar system were completely destroyed in the dimension reduction attack because the human spacecraft could not escape the light speed.

In Cheng Xin's concept, once a person has no humanity and love, he cannot be called a person. She believes that love can save humanity, "In Cheng Xin's subconsciousness, she is a guardian, not a destroyer; she is a woman, not a warrior. She will use her life to guard the balance of the two worlds... until one day, the world no longer needs the dark forest, no longer need a swordman" [15]. Cheng Xin has a kind of almost stupid innocence, and this innocence is the most criticized point by the reader. This character and plot setting can be said to be Cixin Liu's intention, to make Cheng Xin a representative of universal morality and humanity, tell the readers how stupid of the idea that "love can influence everything" with the destruction of the earth and even the solar system. In the doomsday, humanity is not worth mentioning compared with survival.

Looking back at the three types of characters written by Cixin Liu, Cixin Liu used Evans try to save the threat of endangered species by planting tress to express his concern about the environment. At the same time, it was also a denial of the way to save the ecology with environmental protection, and showed his support of space exploration with human beings finally wondering in the universe; and the shaping of Zhang Beihai, Weed and Cheng Xin these two kinds of people, they are the representatives of sensibility and rationality, humanity and survival. Cheng Xin twice pushed humanity into the abyss in the name of love. The persistence of world morality is ultimately a small love. It is far more difficult to sacrifice a personal conscience than Zhang Beihai, it is far more difficult than sacrificing his life, and this is great love. Cixin Liu expresses his concept "Survival First" through their respective value choices and behavioral results. 
In the Trilogy of the "Three Body Problem", whether it is the survival of a grand civilization at a macroscopic level or the individual survival at the micro level, the core of both is inseparable from the concept of survival of Cixin Liu's "Survival first", regardless of whether the civilization or a human individual willing or not, giving up some things in front of the end of the world to ensure that survival is the final outcome. These things may be literary and artistic, or may be human morality. This is tragic, but also rational; Cixin Liu exposed the cruel choices people may need to face in the future in advance.

\section{CONCLUSION}

In summary, the charm of science fiction literature is to show us different dimensions of thinking. At the end of morality is the beginning of science fiction. The "Three Body Problem" uses "a very realistic value and moral system" [18] Pursuing the purely rational view of "Survival first", making the moral choice in sci-fi thinking conflicts with our existing universal moral standards, breaking our existing moral standards, and persuading most of the readers with his own rational systematic logic, causing people to think about the existing scientific and technological development and social ethics, this is the unique point of Cixin Liu's "Three Body Problem" trilogy, and also the significance of the study of the survival theme of "Three Body Problem".

\section{REFERENCES}

[1] Modern Chinese Dictionary (6th Edition) Commemorative Edition [Z]. The Commercial Press, 2012: 1161. (in Chinese)

[2] Xie Zhixi. The persistence of life - existentialism and modern Chinese literature [M]. Beijing: People's Literature Publishing Company, 1999: 9-10. (in Chinese)

[3] Tan Bin, He Guangqun. Course of Ethics [M]. Chengdu: Southwest Jiaotong University Press, 2015 (2): 121. (in Chinese)

[4] Chen Xin. Civilization conflict and Cultural Consciousness - Science Fiction and Reality of "Three Body Problem" [J]. Research in Literary Theory, 2016(1): 94-103. (in Chinese)

[5] Liu Yuan. The Tension of Scientific Thinking and Humanistic Selfexamination - Comment on Cixin Liu's Trilogy of "Three Body Problem"[J].Chinese Modern Literature Research Series,2016(1):193196. (in Chinese)

[6] Luo Yinan. Affection in the Unreal Universe - Analysis of Human Instinct in Cixin Liu's Works [J]. Anhui Literature, 2008(1):30-32. (in Chinese)

[7] Wang Jingjing. On the Cultural Revolution Narrative inCixin Liu's "Three Body Problem" [J]. Fiction Review, 2016(5): 170-175. (in Chinese)

[8] Dong Renwei. Crossing 2012: Review of Chinese Science Fiction Masters[M]. Beijing: People's Posts and Telecommunications Press, 2012 (10): 104. (in Chinese)

[9] Luo Haoling. Cixin Liu Chinese science fiction market has not yet started [N]. Beijing Youth Daily, 2015-03-13 (B5). (in Chinese)

[10] Liu Cixin. Liu Cixin talks about science fiction [M]. Wuhan: Hubei Science and Technology Press, 2014(1): 35,41-42,49,50,105-108. (in Chinese)

[11] Liu Cixin. Rural Teacher [M]. Wuhan: Changjiang Literature and Art Publishing Company, 2012 (9): 1-407. (in Chinese)

[12] Liu Cixin. Wandering Earth [M]. Beijing: China Overseas Chinese Press, 2016 (7): 1-263. (in Chinese)
[13] Li Shanshan. Let us look up at the stars [N]. Southern People Weekly, 2011-05-03 (14). (in Chinese)

[14] Liu Cixin. Three Body Problem [M]. Chongqing: Chongqing Publishing Company, 2008: 267, 255, 205, 232. (in Chinese)

[15] Liu Cixin. Three Body Problem III.Death forever[M].Chongqing: Chongqing Publishing Company, 2010: 394, 451, 382, 136. (in Chinese)

[16] Liu Cixin. Three Body Problem II-Dark Forest [M]. Chongqing: Chongqing Publishing Company, 2008: 446-447, 420. (in Chinese)

[17] Fang Huanfei, Zheng Xiangfu, Feng Haoqing. Contemporary Western Philosophical Thoughts [M]. Hangzhou: Zhejiang University Press, 2013 (1): 182. (in Chinese)

[18] Huang Xiuyi. Cixin Liu: Elitist will only harm science fiction [N] Southern Weekly, 2011-01-30. (in Chinese) 